\title{
BMJ Open Variation in the prevalence of urinary catheters: a profile of National Health Service patients in England
}

\author{
David Clifford Shackley, ${ }^{1}$ Cameron Whytock, ${ }^{2}$ Gareth Parry, ${ }^{3}$ Laurence Clarke, ${ }^{1}$ \\ Charles Vincent, ${ }^{4}$ Abigail Harrison, ${ }^{2}$ Amber John, ${ }^{2}$ Lloyd Provost, ${ }^{5}$ Maxine Power ${ }^{2}$
}

To cite: Shackley DC, Whytock C, Parry G, et al. Variation in the prevalence of urinary catheters: a profile of National Health Service patients in England. BMJ Open 2017;7:e013842. doi:10.1136/ bmjopen-2016-013842

- Prepublication history and additional material are available. To view these files please visit the journal online (http://dx.doi.org/ 10.1136/ bmjopen-2016-013842)

Received 10 August 2016 Revised 1 February 2017 Accepted 9 March 2017

\section{CrossMark}

${ }^{1}$ Department of Urology, Salford Royal Foundation Trust, Salford, UK

${ }^{2}$ Haelo, Salford Royal Foundation Trust, Salford, UK

${ }^{3}$ Institute for Healthcare Improvement, Cambridge, Massachusetts, USA

${ }^{4}$ Department of Experimental

Psychology, University of Oxford, Oxford, UK

${ }^{5}$ Associates in Process Improvement, Austin, Texas, USA

Correspondence to

Dr. Maxine Power;

maxine.power@nhs.net

\section{ABSTRACT}

Introduction Harm from catheter-associated urinary tract infections is a common, potentially avoidable, healthcare complication. Variation in catheter prevalence may exist and provide opportunity for reducing harm, yet to date is poorly understood. This study aimed to determine variation in the prevalence of urinary catheters between patient groups, settings, specialities and over time.

Methods A prospective study (July 2012 to April 2016) of National Health Service (NHS) patients surveyed by healthcare professionals, following a standardised protocol to determine the presence of a urinary catheter and duration of use, on 1 day per month using the NHS Safety Thermometer

Results 1314 organisations (253 NHS trusts) and 9266 284 patients were included. Overall, $12.9 \%$ of patients were catheterised, but utilisation varied. There was higher utilisation of catheters in males $(15.7 \%$ vs $10.7 \%$ $\mathrm{p}<0.001)$ and younger people $(18-70$ year $14.0 \%$ vs $>70$ year $12.8 \% p<0.001)$, utilisation was highest in hospital settings $(18.6 \% p<0.001)$, particularly in critical care (76.6\% $\mathrm{p}<0.001)$. Most catheters had been in situ $<28$ days $(72.9 \% p<0.001)$. No clinically significant changes were seen over time in any setting or specialty. Conclusion Catheter prevalence in patients receiving NHS-funded care varies according to gender, age, setting and specialty, being most prevalent in males, younger people, hospitals and critical care. Utilisation has changed only marginally over 46 months, and further guidance is indicated to provide clarity for clinicians on the insertion and removal of catheters to supplement the existing guidance on care.

\section{BACKGROUND}

Harm from urinary catheters and associated urinary tract infection is common. Variation in catheter prevalence between patient groups, settings and specialties may exist with studies reporting a catheterisation rate of $12 \%-26 \%$ among hospitalised patients. ${ }^{1-4}$ Yet surprisingly limited information exists with respect to the variation in catheter prevalence. While potentially beneficial for some patients, urinary catheters may be inserted without robust clinical indication in $30 \%-50 \%$ of cases. ${ }^{5-10}$

\section{Strengths and limitations of this study}

- The size of the study is unique, measuring the prevalence of urinary catheterisation in over 9 million patients over time.

- Previous work has predominantly focused on the insertion of catheters (incidence), our study adds to this by providing an understanding of the scale of utilisation (prevalence).

- Different interpretations of operational definitions by clinical staff or desirability bias could influence results by either over or underestimating prevalence.

- Fixed protocols for data collection resulted in the absence of some key information, for example, the reason for insertion of catheters.

- A full comparison with other studies or data systems is not possible because operational definitions differ.

Additionally, even when patients do meet appropriateness criteria for urinary catheterisation, they often remain in place for longer than necessary. ${ }^{11}$ Despite evidencebased guidance, ${ }^{12} 13$ a plethora of practices exists in the management of urinary catheters, especially in hospital settings and may explain some of the variation. The decision to catheterise a patient is usually taken by clinical staff and management is overseen by nurses, other healthcare professionals and the patient themselves. Handoffs in maintenance of catheters provide opportunities for error and protocol deviations. For this reason, diligent review of the primacy, purpose and utility of catheters is required in all settings to ensure prompt removal. Variations in prevalence may help us to understand the variation in practice and offer opportunity for learning and improvement. This study aimed to determine variation in the prevalence of urinary catheters between patient groups, settings, specialities and over time. 


\section{METHODS}

\section{Setting}

The National Health Service (NHS) in England offers funded care for 54.3 million residents, employs 1.2 million staff and deals with 15 million hospitalised patients per year. ${ }^{14}$ Services are provided in a wide range of settings including hospitals (providing care to inpatients) and community care providers (providing care within patient homes, nursing homes and community hospitals). This study prospectively surveyed patients receiving NHS care from across the entire system, including patient's own homes.

\section{Timeline}

Data collection started in July 2012 and is ongoing. All participating organisations and patients from the start of collection up to April 2016 (3 years, 10 months) are included.

\section{Participants}

All NHS providers were invited to participate. Organisations joined the survey voluntarily in 2012 and hospitals were incentivised to collect data between July 2012 and March 2015 through a national pay for performance scheme, Commissioning for Quality and Innovation. ${ }^{15}$ Since April 2015, data collection has been voluntary.

\section{Data collection}

Once each month, frontline clinicians from participant organisations were asked to collect data on $100 \%$ of patients receiving NHS-funded care regardless of whether they were perceived to be at risk for harm. For each patient, information on gender (male/female), age band $(<18,18-70$ and $>70$ years), location (hospital ward, community, hospice, nursing home, patient home or residential care home), clinical specialty (medical, surgical, mental health, critical care, emergency department, paediatrics, obstetrics or other) and four harms (pressure ulcers, falls, urinary infection in patients with catheters and venous thromboembolism) were collected. No patient identifiable data were collated. Information was sourced from examination, patient report and clinical records. Data on catheters are reported in this article, other harms will be reported separately.

Specifically, to determine if a patient had a urinary catheter, clinicians examined the patient, reviewed medical records and spoke to the patient to determine whether a catheter was present. Patients were included in the sample if an indwelling urethral urinary catheter was in place on the day of the survey, or if one had been removed in the previous 72 hours. If a patient was included as having a catheter, staff recorded the length of time the catheter had been in place ( $<28$ days, $>28$ days, days not known). Patients with supra-pubic catheters and other stents were excluded. These are the precise operational definitions that are provided with the tool to promote consistency in data collection and attempt to mitigate bias. Additional criteria for exclusion by place or specialty can be reviewed online. $^{16}$

\section{Measurement instrument}

The NHS Safety Thermometer is a Visual Basic application of MS Excel (Excel 97-2003 onwards) and is self-contained with no requirements for a network connection. The instrument can be used in any location across a range of settings and takes less than $10 \mathrm{~min}$ to complete per patient. Primarily, this application is used for frontline data collection, charting and reporting. The interface is designed to validate data during submission and minimise user burden through the use of drop-down lists and cross-validation checks. The user interface forces data entry of all measures so it is not possible to submit partial data. It also permits immediate evaluation of the data and includes four data views, including a survey form, summary dashboard, time series charts and a comparison report. Additionally, it offers a merge function, allowing data to be aggregated and viewed at the ward, organisational, regional or national level. Guidance is provided within the instrument itself and in companion documentation designed to address common questions. ${ }^{1516}$

\section{Data submission}

The data for all patients surveyed in one unit were entered into one data collection file. For each clinical unit, a safety thermometer excel file of all patients surveyed on 1 day was submitted to a named site coordinator. The site coordinator was the registered user who collated files from all clinical units, merged them into an organisational file and submitted data to the Health and Social Care Information Centre (HSCIC).

The data were validated during data entry by the local lead, by the site coordinator prior to submission to HSCIC and finally by the HSCIC. Once all surveys were submitted and validated, they were merged into cumulative national statistics. National statistics are published with open access files that allow data to be reviewed and analysed (https://www.safetythermometer.nhs.uk/; www. hscic.gov.uk). These files have been used for this analysis.

\section{Data analysis}

Descriptive statistics were used to describe the population(s) surveyed. Percentages were calculated from the denominator (total number of patients surveyed) unless otherwise stated. Comparative statistics were used to describe variation between subgroups, $\mathrm{p}$ values $<0.05$ were considered significant.

\section{Variation over time}

Data were presented in statistical process control charts as a proportion (monthly) over time. ${ }^{17}$ Patterns of variation, unlikely to occur by chance alone, were identified 'a priori' (see online supplementary table 1 ) as 'special cause'. The line of central tendency (mean) was used to determine special cause variation and reset following episodes of special cause variation. The amplitude of change was calculated from the difference between the two means. 


\section{Subgroup analysis}

Secondary analysis on subgroups by setting and specialty were conducted. Inclusion and exclusion criteria are available in online supplementary table 2 .

\section{Setting}

Ten rational subgroups were analysed (acute hospital, community, community hospital, hospice, mental health community, mental health ward, nursing home, patient home, residential care home and other) and used for the surveyed population description. Further analysis of three clusters of settings: all hospital (acute hospital and community hospital), all community (community, nursing home, patient home and residential care home) and hospice was also undertaken.

\section{Specialties}

Data were categorised into eight subgroups (medical, surgical, mental health, critical care, emergency department, paediatrics, obstetrics and other) by a clinical expert (DS). Five clusters (medical, surgical, critical care, obstetrics and emergency department) were analysed in detail. For specialty subgroupings, see online supplementary table 3 .

Comparisons of average catheter use were made between subgroups (age, gender, setting and specialty) using negative binomial regression, clustered on organisation.

\section{Ethical approval}

This study is a secondary analysis of publically available deanonymised data. No ethical approval was required.

\section{RESULTS}

\section{Population description}

Reviewed were 9266284 NHS patients over the study period (2012: 1023875 ; 2013: 2448146 ; 2014: 2531555 ; 2015: 2459601 and 2016: 803107). The population characteristics are presented in table 1 . The number of patients surveyed by setting is available for view in online supplementary table 4 .

\section{Population characteristics \\ Gender}

Overall males were more likely to have a catheter in place than females $(15.7 \%$ vs $10.7 \%, \mathrm{p}<0.001)$. This finding was also evident in hospitalised and community patients (20.6\% vs $16.9 \%, \mathrm{p}<0.001 \%$ and $10.6 \%$ vs $4.6 \%, \mathrm{p}<0.001$, respectively). Only in one cluster (hospice) was there no difference in catheter prevalence between males and females $(24.2 \%$ vs $24.5 \%, \mathrm{p}=0.821)$ (figure 1$)$.

\section{Age}

Overall, patients $18-70$ years were more likely to have a catheter than $>70$ years $(14.0 \%$ vs $12.8 \%, \mathrm{p}<0.001)$. This varied by healthcare setting. In hospitals, patients $>70$ years were more likely to have a catheter than 18-70years (20.8\% vs $17.5 \%, \mathrm{p}<0.001)$. In the community, patients of $18-70$ years were more likely to have a catheter

Table 1 Overall population characteristics

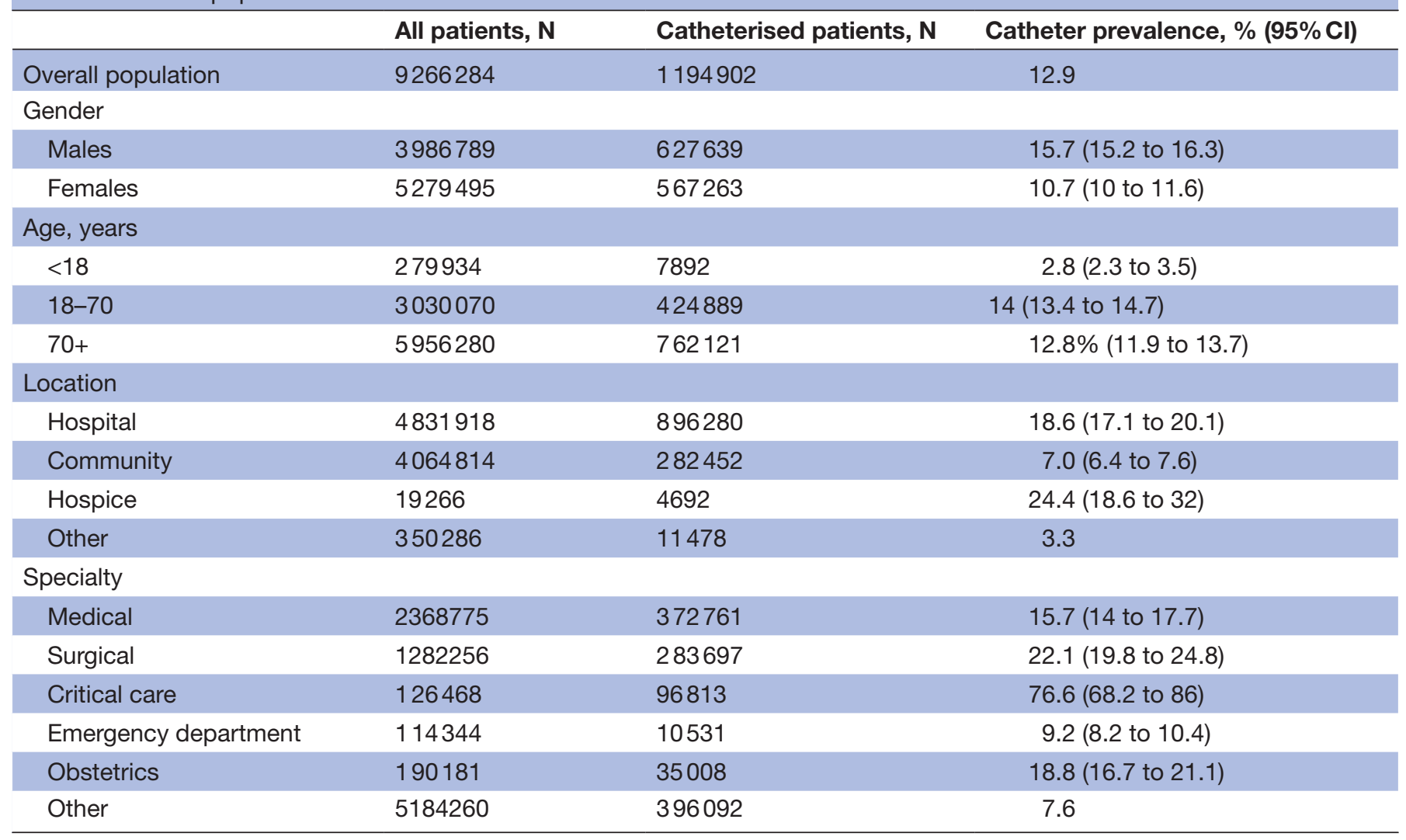




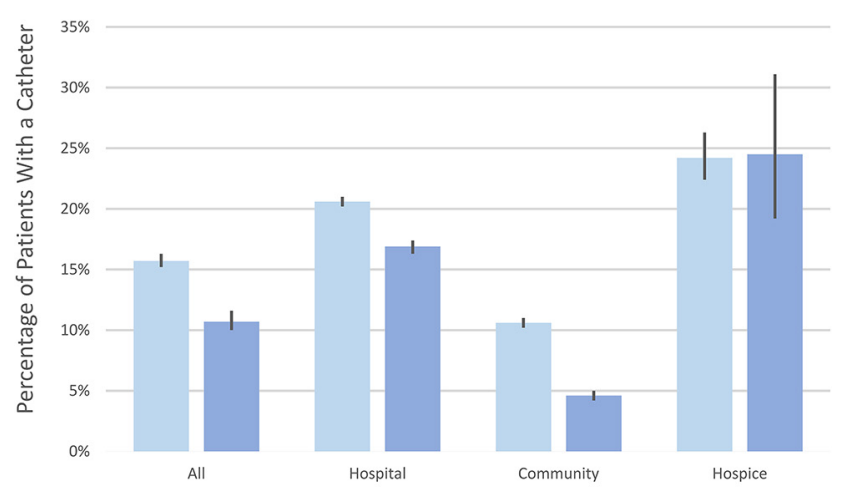

Male $₫$ Female

Figure 1 Gender differences in catheter prevalence by setting.

than $>70$ years $(8.6 \%$ vs $6.5 \%, \mathrm{p}<0.001)$. In hospices patients $>70$ years were more likely to have a catheter than $18-70$ years $(26.0 \%$ vs $22.6 \%, \mathrm{p}=0.006)$ (figure 2 ).

\section{Catheterised patients}

The proportion of catheterised patients who were male was significantly greater in community settings than hospital and hospices $(60.5 \%, 49.9 \%$ and $48.5 \%$, respectively, $\mathrm{p}<0.001$ ) ( see online supplementary figure 1).

\section{Duration}

In total, catheterised patients were more likely to have had a catheter in place for $<28$ days than $>28$ days $(72.9 \%$ vs $22.2 \%, \mathrm{p}<0.001$ ), with the length of time unknown in a small percentage $(5.2 \%)$. In hospitals, catheterised patients were more likely to have had a catheter in place for $<28$ days than $>28$ days $(81.2 \%$ vs $14.2 \%, \mathrm{p}<0.001$, unknown length of time in $3.9 \%$ ). Conversely in the community, catheterised patients were more likely to have had a catheter in place for $>28$ days than $<28$ days $(64.3 \%$ vs $28.3 \%, \mathrm{p}<0.001$, unknown length of time in $12.0 \%$ ). In hospices, patients' catheters were, like hospitals, more likely to be short term with most having been in place for $<28$ days than $>28$ days $(62.6 \%$ vs $22.9 \%, \mathrm{p}<0.001$, unknown length of time in $13.8 \%$ ) (figure 3 ).

\section{Setting description}

One thousand three hundred and fourteen organisations registered to use the NHS Safety Thermometer and

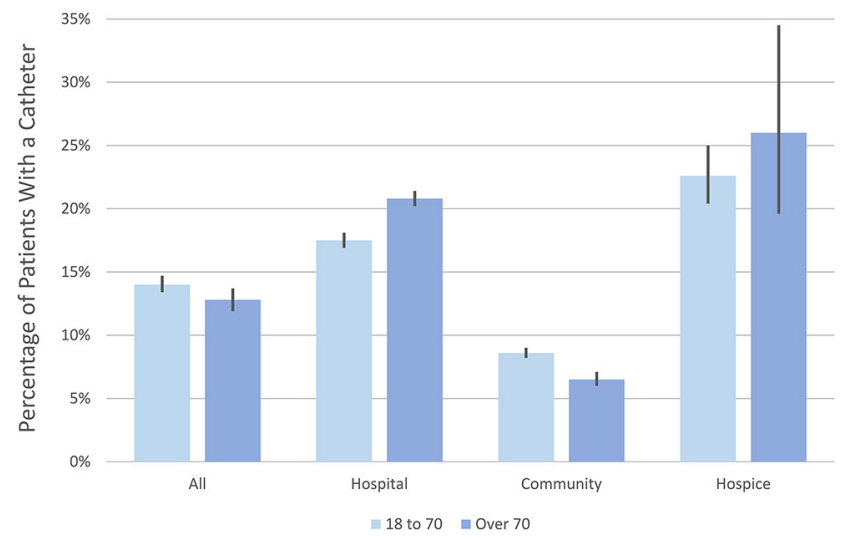

Figure 2 Age differences in catheter prevalence by setting.

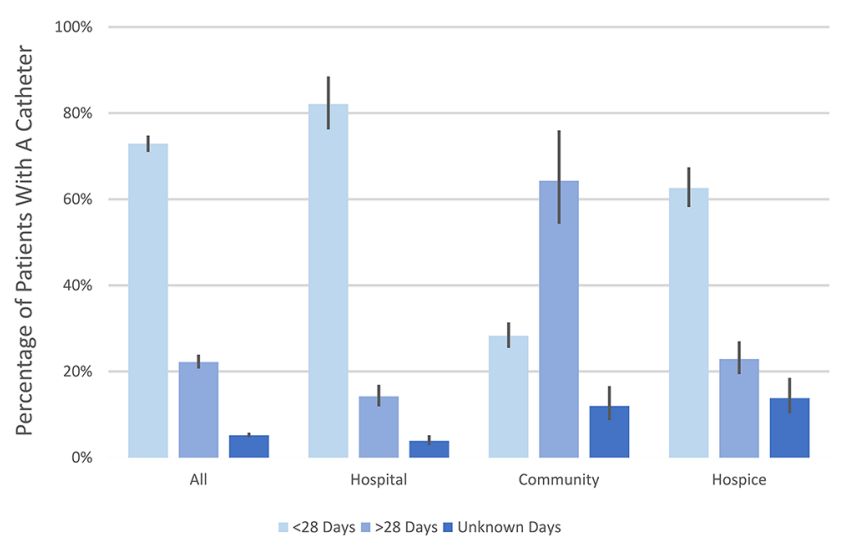

Figure 3 Number of days of catheter placement by setting.

supplied at least 1 month of data. The number of organisations submitting at least 1 month of data under each setting is shown in online supplementary table 4. Organisations can submit under more than one setting for different hospitals, departments or services within their organisational umbrella. The number of data submissions each year by setting is available for view in online supplementary table 5 .

\section{Healthcare profiles}

\section{Setting}

Overall $12.9 \%$ of patients had a catheter. In hospitals $18.6 \%$ of patients had catheters, in the community $7.0 \%$ had catheters and in hospices $24.4 \%$ had catheters $(\mathrm{p}<0.001)$. Percentages by year are available in online supplementary table 6 .

\section{Specialty}

The highest prevalence of catheters was in critical care $(76.6 \%)$, followed by surgical specialties $(22.1 \%)$, obstetrics $(18.8 \%)$, medical specialties $(15.7 \%)$ and emergency departments $(9.2 \%)(\mathrm{p}<0.001)$.

\section{Change over time}

\section{Setting}

Minor changes occurred in the percentage of catheterised patients in both hospital and community settings (figure 4 ). Percentage changes from baseline were $<1 \%$ in all settings.

\section{Specialty}

Minor changes occurred in the percentage of catheterised patients in different specialties (figure 5). Percentage changes from baseline were generally small, the largest being a $1.6 \%$ increase in catheter presence in critical care settings, from $75.7 \%$ to $77.3 \%$ in December 2014.

\section{DISCUSSION}

Our results indicate that urinary catheters are highly ubiquitous within our healthcare system, with 1 in 5 patients in hospital and 1 in 14 in community care catheterised. Catheters are more prevalent in males overall. In hospital settings, catheters are most prevalent in patients aged over 70; the majority have been in situ for $<28$ days. The 


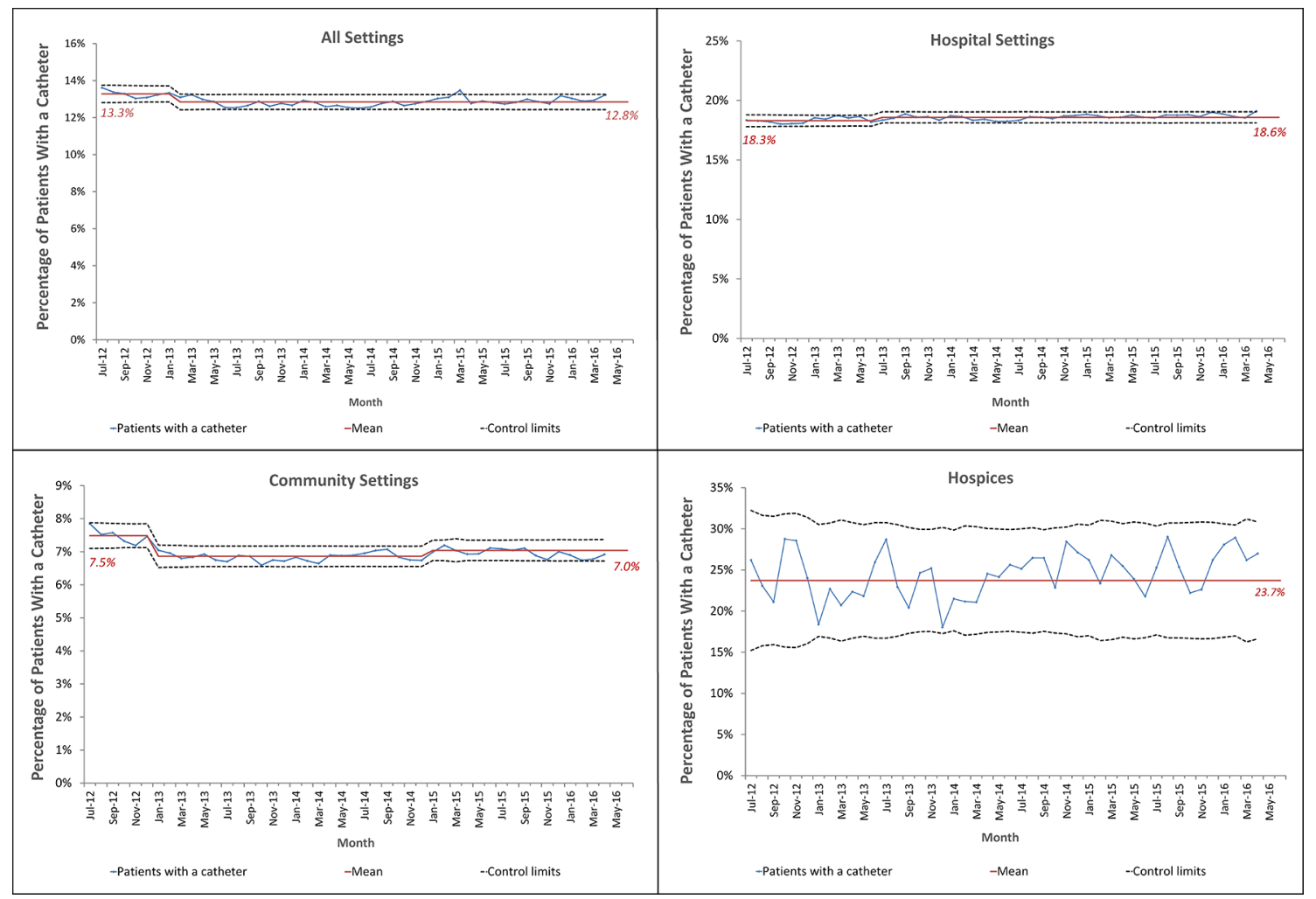

Figure 4 Temporal changes in catheter prevalence by setting.

highest prevalence is in critical care, where over $70 \%$ of patients have a catheter in situ. This contrasts with out of hospital (community) settings where catheters are more prevalent in people between the ages of 18 and 70 years and where the majority have been in situ for $>28$ days. Catheter prevalence has changed only marginally over 46 months. The method used in our study, of repeatedly measuring catheter prevalence, offers insights into both the nature of catheterisation and temporal changes in observed patterns.

First, our observation that males have more catheters than females may seem somewhat counterintuitive. Two studies of catheters in the emergency room demonstrated higher rates of catheters in females. ${ }^{18}{ }^{19}$ However, closer examination of method reveals that these studies examine the insertion of new catheters (incidence) rather than the number of patients with a catheter at a given point in time (point prevalence). It is, therefore, reasonable to conclude that while more women have catheters inserted in specific settings, in the healthcare population overall there are more catheters in men than women. When looking at gender differences in hospitalised patients, our results are similar to available comparable data. ${ }^{20}$ Our study was carried out as part of a large-scale measurement of the prevalence of harm in healthcare, with catheters being only one of four measures. ${ }^{15} 16$ The opportunity to gather detailed information, for example the reason for insertion of catheters, was not possible. Further studies are required to explore the reasons for insertion of catheters. However, the increased prevalence in men can be explained. Males are susceptible to prostate disease, have longer urethras than women, are more likely to go into retention especially postoperatively ${ }^{21}$ and have increased likelihood of long-term catheterisation.

Catheters are more prevalent in patients under the age of 70 years in community settings. One possible explanation for this is the nature of the NHS population surveyed. It is important to note that all patients surveyed 'out of hospital' were in receipt of care from a healthcare professional on the day of the survey. They are not representative of the community overall, but of a specific subgroup who may well have just been discharged from an in-patient setting, have increased chronic disease or disability. This may also account for the increased duration of catheter use. Guidelines for catheter maintenance have been published and widely accepted for several years. ${ }^{12} 13$ There is a clear association between catheter days and increased infection risk. Current practice guidelines suggest diligent monitoring of catheter days to reduce such risk. It is somewhat surprising that there was a small but not insignificant group of patients for whom it was impossible to determine how long their catheter had been in situ. Once again, the reasons for this are likely to be multifactorial and may include challenges with recording, reporting or information handover. Irrespective, it would seem that the marker of excellent care would be to ensure that the duration of catheter use is understood in all patients.

Our study demonstrates no clinically significant changes in the prevalence of catheters over the 46 months of our study. This may seem disappointing given the available guidance for management of catheters but we cannot 


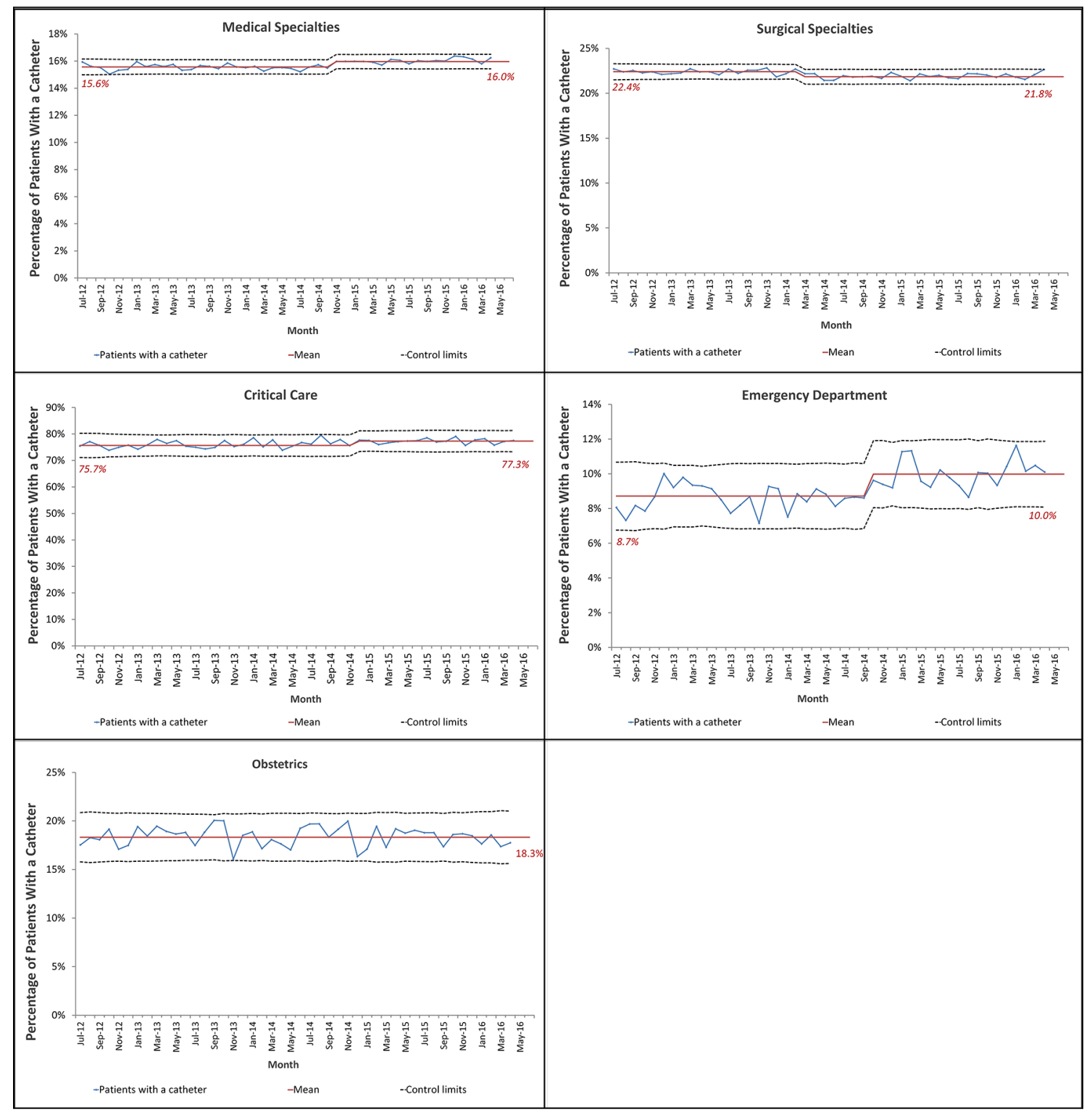

Figure 5 Temporal changes in catheter prevalence by specialties within hospital settings.

conclude that our results represent a failed attempt at improvement. Our interaction with participants in our study suggests that current guidance provides clarity on the management of catheters, once they have been inserted, but the clinical decision to insert or remove a catheter is still largely left to local decision makers. Healthcare professionals and policymakers may wish to address this in the future. Clearer clinical standards for the insertion and removal of urinary catheters may help reduce the prevalence of catheters overall. Our findings are consistent with previous literature suggesting that confusion exists among clinicians about when a catheter is appropriate. ${ }^{7-10}$ While these temporal findings are disappointing, establishing the nature of the secular trend may prove to be a helpful baseline for national policy initiatives focused on reducing the prevalence of catheters.

\section{Strengths and limitations}

This is the first study of catheter prevalence at a national level, and its inclusion of nine million patients is, to our knowledge, unprecedented. Our study allows us, for the first time, to examine patterns and trends in the use of catheters in the NHS demonstrating higher utilisation in males, younger patients, hospital settings and critical care specialties. We have been able to show that further attention needs to be paid to variation in patterns of utilisation. The observed patterns have remained consistent over time and can be used as a benchmark of current practice. Our study calls for a review of the practice standards and guidelines for insertion and removal of urinary catheters and adds to our understanding of urinary catheterisation across the whole health economy.

One limitation of this study is that data were collected by frontline healthcare professionals. Slight differences in interpretation of operational definitions of measures, particularly the inclusion of patients without a catheter but catheterised in the last 72 hours, could affect documented catheterisation prevalence. Also although staff were asked to survey all patients under their care, we do 
not know if this occurred and it is possible some patients were missed, representing a potential source of selection bias. Patients who no longer had a catheter in situ (but had in the past 72 hours) were included because they are at increased risk of infection in the period immediately after removal. This could lead to an overestimation in the overall prevalence reported in this study. In addition, as staff know the data can be viewed at a unit level, a desirability bias may apply, resulting in under-reporting of measured variables. Training and guidance alone may be inadequate in assuring consistency of data collection. ${ }^{22}$

A further limitation is that caution needs to be taken in generalising these findings to other healthcare systems. The case mix in hospitals in the UK is changing rapidly. The scale of this study does not permit a detailed description of context that would be needed to make direct comparisons. In addition, The NHS Safety Thermometer does not collect any patient identifiable data, consequently demographic and time variables are collected as categorical rather than continuous data. There is, therefore, only limited opportunity to apply case-mix adjustment. It was not possible to collect important information such as catheter days, the reason for catheterisation or the appropriateness of catheterisation. We recognise this is important information that would help explain our findings in more detail.

\section{CONCLUSION}

Catheterisation in patients receiving NHS-funded care is variable depending on a number of factors including gender, age, setting and specialty. In hospitals, catheters are more prevalent in males, patients aged over 70 years and critical care, but the majority of catheters have been in situ for $<28$ days. This contrasts without of hospital (community) settings where catheters are still more prevalent in males but between the ages of 18 and 70 years and have been in situ for $>28$ days. Catheter prevalence has changed only marginally over 46 months, and further guidance is indicated to provide clarity for clinicians on the insertion and removal of catheters to supplement the existing guidance on care. Caution needs to be taken in generalising these results to the entire UK population.

Correction notice This paper has been amended since it was published Online First. Owing to a scripting error, some of the publisher names in the references were replaced with 'BMJ Publishing Group'. This only affected the full text version, not the PDF. We have since corrected these errors and the correct publishers have been inserted into the references.

Acknowledgements The authors would like to thank Haelo data co-ordinator, Nick John, for his analytic work and for assisting with editing the manuscript.

Contributors DCS: Involved in all stages of data collection, data analysis and drafting the article. Substantial contributions to the clinical content of the work. CW: Involved in data analysis and drafting the article; involved in responding to reviewer comments. GP: Statistical analysis and manuscript preparation. LC: Involved in data analysis and revising final manuscript; contributed to the clinical content of the work. CV: Content advisor and contributor (Patient Safety and Patient Safety Measurement); contributions to content development and revised final manuscript. $\mathrm{AH}$ : Lead on data collection, field training and analysis. AJ: Assisted with data work and drafting the article. LP: Contributed advice and expertise relating to the statistical content of the work. MP: Substantial contributions to the initial conception and design of the cohort; involved in the analysis and interpretation of data and in drafting and revising the article for content.

Funding This work was supported by The Department of Health (QIPP programme, 2010-14) and NHS England (Patient Safety Division).

Competing interests CV reports personal fees from Haelo during the conduct of the study and carries out occasional paid consultancy work on patient safety, though not related to this paper.

Provenance and peer review Not commissioned; externally peer reviewed.

Data sharing statement Data are open-access and publicly available. These can be accessed online at: www.safetythermometer.nhs.uk and www.hscic.gov.uk. We encourage collaboration with individual sites aiming to undertake local work designed to reduce unnecessary catheter use. We also encourage collaboration between different organisations, whereby sites with markedly high catheter use may learn 'best practice' strategies from organisations which are performing better.

Open Access This is an Open Access article distributed in accordance with the Creative Commons Attribution Non Commercial (CC BY-NC 4.0) license, which permits others to distribute, remix, adapt, build upon this work non-commercially, and license their derivative works on different terms, provided the original work is properly cited and the use is non-commercial. See: http://creativecommons.org/ licenses/by-nc/4.0/

(c) Article author(s) (or their employer(s) unless otherwise stated in the text of the article) 2017. All rights reserved. No commercial use is permitted unless otherwise expressly granted.

\section{REFERENCES}

1. Saint S, Wiese J, Amory JK, et al. Are physicians aware of which of their patients have indwelling urinary catheters? Am J Med 2000;109:476-80.

2. Weinstein JW, Mazon D, Pantelick E, et al. A decade of prevalence surveys in a tertiary-care center: trends in nosocomial infection rates, device utilization, and patient acuity. Infect Control Hosp Epidemiol 1999;20:543-8.

3. Magill SS, Edwards JR, Bamberg W, et al. Emerging infections program Healthcare-Associated infections and antimicrobial use prevalence survey Team. multistate point-prevalence survey of health care-associated infections. $N$ Engl J Med 2014:27:370:1198-208.

4. Gardner A, Mitchell B, Beckingham W, et al. A point prevalence cross-sectional study of healthcare-associated urinary tract infections in six Australian hospitals. BMJ Open 2014;4:e005099.

5. Jain P, Parada JP, David A, et al. Overuse of the indwelling urinary tract catheter in hospitalized medical patients. Arch Intern Med 1995;155:1425-9.

6. Gardam MA, Amihod B, Orenstein P, et al. Overutilization of indwelling urinary catheters and the development of nosocomial urinary tract infections. Clin Perform Qual Health Care 1998;6:99-102.

7. Munasinghe RL, Yazdani H, Siddique M, et al. Appropriateness of use of indwelling urinary catheters in patients admitted to the medical service. Infect Control Hosp Epidemiol 2001;22:647-9.

8. Gokula RR, Hickner JA, Smith MA. Inappropriate use of urinary catheters in elderly patients at a midwestern community teaching hospital. Am J Infect Control 2004;32:196-9.

9. Tiwari MM, Charlton ME, Anderson JR, et al. Inappropriate use of urinary catheters: a prospective observational study. Am J Infect Control 2012;40:51-4.

10. Greene MT, Kiyoshi-Teo H, Reichert H, et al. Urinary catheter indications in the United States: results from a national survey of acute care hospitals. Infect Control Hosp Epidemiol 2014;35(Suppl 3):S96-S98.

11. Knoll BM, Wright D, Ellingson L, et al. Reduction of inappropriate urinary catheter use at a Veterans Affairs hospital through a multifaceted quality improvement project. Clin Infect Dis 2011;52:1283-90.

12. Loveday HP, Wilson JA, Pratt RJ, et al. epic3: national evidencebased guidelines for preventing healthcare-associated infections in NHS hospitals in England. J Hosp Infect 2014;86(Suppl 1):S1-S70.

13. National Institute for Health and Care Excellence. Healthcareassociated infections: prevention and control in primary and community care. 2012. https://www.nice.org.uk/guidance/cg139 (accessed 21 Oct 2016). 
14. Key statistics on the NHS. NHS Confederation. 2016. http://www. nhsconfed.org/resources/key-statistics-on-the-nhs (accessed 21 Oct 2016).

15. Classic | Harm Free Care. Harmfreecareorg. 2016 http:// harmfreecare.org/measurement/nhs-safety-thermometer/ (accessed 21 Jun 2016).

16. Department of Health. Delivering the NHS safety thermometer CQUIN 2012/13: a preliminary guide to measuring 'harm free' care. London, 2012. https://www.gov.uk/government/publications/ delivering-the-nhs-safety-thermometer-cquin-2012-13. (accessed 11 Nov 2016).

17. Provost LP, Murray S. The health care data guide: learning from data for improvement. San Francisco: John Wiley \& Sons, 2011.
18. Fakih MG, Shemes SP, Pena ME, et al. Urinary catheters in the emergency department: very elderly women are at high risk for unnecessary utilization. Am J Infect Control 2010;38:683-8.

19. Schuur JD, Chambers JG, Hou PC. Urinary catheter use and appropriateness in U.S. emergency departments, 1995-2010. Acad Emerg Med 2014;21:292-300.

20. Jansen IA, Hopmans TE, Wille JC, et al. Appropriate use of indwelling urethra catheters in hospitalized patients: results of a multicentre prevalence study. BMC Urol 2012;12:25.

21. Tammela T, Kontturi M, Lukkarinen O. Postoperative urinary retention. I. incidence and predisposing factors. Scand J Urol Nephrol 1986;20:197-201

22. Power M, Fogarty M, Madsen $\mathrm{J}$, et al. Learning from the design and development of the NHS Safety Thermometer. Int J Qual Health Care 2014;26:287-97. 